ASSISTED VENTILATION

\title{
Domiciliary non-invasive ventilation for recurrent acidotic exacerbations of COPD: an economic analysis
}

\author{
J M Tuggey, P K Plant, M W Elliott
}

Thorax 2003;58:867-871

See end of article for authors' affiliations .....................

Correspondence to: DrMW Elliott, Department of Respiratory Medicine, St James's University Hospital, Beckett Street, Leeds LS9 7TF, UK; mark_w.elliott@leedsth. nhs.uk

Revised version received 1 December 2002 Accepted for publication 11 July 2003

\begin{abstract}
Background: Patients with chronic obstructive pulmonary disease (COPD) pose a significant burden to healthcare providers with frequent exacerbations necessitating hospital admission. Randomised controlled data exist supporting the use of acute non-invasive ventilation (NIV) in patients with exacerbations of COPD with mild to moderate acidosis. The use of NIV is also described in chronic stable COPD, with evidence suggesting a reduction in hospital admissions and general practitioner care. We present economic data on the impact of domiciliary NIV on the need for admission to hospital and its attendant costs.

Methods: A cost and consequences analysis of domiciliary NIV based on a before and after case note audit was performed in patients with recurrent acidotic exacerbations of COPD who tolerated and responded well to NIV. The primary outcome measure was the total cost incurred per patient per year from the perspective of the acute hospital. Effectiveness outcomes were total days in hospital and in intensive care.

Results: Thirteen patients were identified. Provision of a home NIV service resulted in a mean (95\% Cl) saving of $£ 8254$ ( $£ 4013$ to $£ 12495$ ) (€11 720; $€ 5698$ to $€ 17743$ ) per patient per year. Total days in hospital fell from a mean (SD) of $78(51)$ to $25(25)(p=0.004)$, number of admissions from 5 (3) to 2 (2) $(p=0.007)$, and ICU days fell from a total of 25 to $4(p=0.24)$. Outpatient visits fell from a mean of 5 (3) to $4(2)(p=0.14)$.

Conclusions: This study suggests that domiciliary NIV for a highly selected group of COPD patients with recurrent admissions requiring NIV is effective at reducing admissions and minimises costs from the perspective of the acute hospital. Such evidence is important in obtaining financial support for providing such a service.
\end{abstract}

$\mathrm{P}$ atients with chronic obstructive pulmonary disease (COPD) represent a significant burden to healthcare providers. They may have frequent exacerbations, often necessitating admission to hospital. Each admission has been estimated to cost $£ 3000$, ${ }^{1}$ and it will be much more expensive if the patient requires intensive care. There is now a cohort of randomised controlled trials ${ }^{2-8}$ and a systematic review ${ }^{9}$ supporting the use of acute non-invasive ventilation (NIV) in patients with an exacerbation of COPD with mild to moderate acidosis. An average district general hospital with a catchment population of 250000 and a standardised mortality rate for COPD of 100 will treat approximately six patients per month who present to hospital with a respiratory acidosis with NIV (this figure does not include patients who deteriorate after admission); $20 \%$ will be readmitted at least once in the following year and the median survival is of the order of 15 months. ${ }^{10}$ These patients therefore represent a group at high risk of death who consume significant healthcare resources.

The use of NIV has been described in chronic stable COPD and there is some evidence of a reduction in the need for hospital and general practitioner care, ${ }^{11-13}$ but there are few published long term randomised controlled trials. ${ }^{14}{ }^{15}$ At this centre a small subgroup of patients with severe COPD with recurrent admissions due to respiratory acidosis, during which they have required NIV acutely (according to recognised criteria $^{5}$ ) and who have tolerated it well, have requested or been offered domiciliary NIV with the aim of reducing the number of future hospital admissions. We present data on the impact of domiciliary NIV on the need for hospitalisation and its attendant costs.
The aim of the study was to compare the effectiveness and costs of domiciliary NIV with conventional treatment in a group of patients with recurrent admissions because of an acidotic exacerbation of COPD. The evaluation was limited to the perspective of the acute hospital (a university teaching hospital serving a population of 500 000). Only costs borne by the hospital were identified and valued. Costs to the patient, family, and to the primary care physician were not included. The primary outcome measure was the total cost incurred per patient per year. Measured consequences were total days in hospital and in intensive care. In addition, an estimate of survival was performed based on patients using home NIV.

\section{METHODS}

A cost and consequences analysis based on a year before and year after case note audit was performed.

\section{Subjects}

Patients admitted frequently to hospital requiring inpatient NIV for an acidotic ( $\mathrm{pH}<7.35$ ) exacerbation of COPD, who tolerated and responded to it well, and who requested or were offered the option of domiciliary NIV formed the study group. Patients who tolerated inpatient NIV poorly were either not offered or declined home treatment. This was therefore a highly selected group. All patients who had received domiciliary NIV at this centre for this indication between the years 1995 and 2000 were identified from a database. Medical case records were retrieved for these patients from both this hospital and from the local (to the patient) hospital where appropriate. Duration of all inpatient episodes including "NIV days", "conventional days", and 
"intensive care days" were recorded for each episode from entries in the clinical notes and from the hospital computerised patient administration system. Admission arterial blood gas tensions were recorded for each episode and a record was made of all respiratory outpatient attendances during the study period, including spirometric indices and stable arterial blood gas tensions where available. If patients on home NIV attended for elective "check" sleep studies, these were also included in the analysis in terms of days in hospital.

\section{Costs}

Four main types of cost were identified and valued: hospital admission (either acute inpatient NIV or acute inpatient conventional treatment), intensive care treatment, and chronic home NIV.

\section{Hospital admission}

The days in hospital were identified retrospectively from case notes and valued using costings from a previous cost effectiveness analysis of NIV for acute exacerbations of COPD performed alongside a randomised controlled trial. ${ }^{16}$ In this study the cost of a day in hospital was based on nursing and medical staff costs, pharmacy costs, investigation costs, and hotel costs. Hotel costs included heating, lighting, food, repairs, the costs of building, and administration overhead costs such as salaries and wages. Nursing time in the study by Plant et al was measured by an end of bed log of all nursing activity. ${ }^{16}$ This was valued by assessing the ward duty roster and bed base, and calculating a "per shift" cost based on the ward nursing budget derived from the respective hospital finance departments. Hotel costs were obtained from hospital finance departments and valued in a "top down" approach. Pharmacy costs were obtained from those cited in the British National Formulary $(\mathrm{BNF})^{17}$ for a standard prescription of salbutamol $5 \mathrm{mg}$ and ipratropium bromide $500 \mu \mathrm{g}$ four times a day. Additional treatments such as aminophylline were valued from the BNF. Investigation costs related to an acute exacerbation of COPD (arterial blood gas analysis, chest radiography, sputum culture and blood tests) were not measured since they were felt to be negligible in comparison with the total costs incurred (this would bias against any cost benefit of domiciliary NIV). The mean cost for each day on an intensive care unit was derived from hospital finance departments.

Daily hospital costs for inpatient conventional treatment and intensive care treatment based on the above measurements were valued according to the relevant hospital and as appropriate for each patient episode identified from the medical records. Valuations were corrected for inflation to the financial year 1999/2000 using the Health Services Cost Index. $^{18}$

\section{Inpatient ventilation}

All patients received acute NIV during exacerbations of their disease. The capital cost of purchasing NIV machines (NIPPY 2, B \& D Electromedical, UK) was discounted to allow for a 5 year lifespan at the UK Treasury recommended rate of $6 \%{ }^{19}$ Ward consumables (consisting of a range of different sized masks, headgear and tubing) were discounted for a 2 year lifespan. The additional nursing time of setting up NIV and recurring costs of machine servicing and equipment sterilising was obtained from the work of Plant et al ${ }^{16}$ An estimate of the cost of training nursing staff in the use of NIV is included, based on nursing workload data. ${ }^{16}$

\section{Home ventilation}

Provision of home NIV requires the supply of a ventilator (NIPPY 2) for each patient to use regularly at home, together with associated equipment such as a humidifier (HC100, Fisher \& Paykel, UK), tubing, mask and medical, nursing and technical support. Home ventilators are the same as those used for acute NIV and were therefore valued in the same way. Masks and tubing were discounted for an 8 month lifespan (estimated lifespan within this unit).

\section{Outpatient attendances}

Within the study centre outpatient support to patients with home NIV is provided by a respiratory nurse specialist $(\mathrm{H}$ grade, 4 th increment point, i.e. senior clinical nurse). It was estimated that they spent approximately 1 hour per week involved in direct care or administration relating to home NIV for COPD patients (3\% of a 37.5 hour working week). Outpatient attendances were valued per visit using the mean total cost derived from the hospital which included capital cost of buildings, equipment, doctor, nursing, and clerical staff time.

\section{Analysis of data}

\section{Statistical analysis}

Data were analysed using Access 2000 and SPSS Version 10. Normally distributed data are reported as means with $95 \%$ confidence intervals (95\% CI). Non-normally distributed data are expressed as medians with 5 th and 95 th centiles. All tests and $\mathrm{p}$ values are two tailed. A paired $t$ test was used for within patient comparison of before versus after home NIV. Survival was estimated using a Kaplan-Meier plot based on events (i.e. death) in the years following commencement of home NIV.

\section{Economic analysis}

The total cost per patient in the year before (conventional treatment) and the year after commencing home NIV was determined.

\section{Sensitivity analysis}

Economic evaluations are often based on estimates. By subjecting the analysis to varying effects of uncertainty, the sensitivity of the analysis to different estimates can be assessed. If large variations in the assumptions do not produce significant changes in the results, then there can be greater confidence in the accuracy of the original results. The conclusion was tested for sensitivity against the number of admissions during the NIV year, the length of stay per admission, and the length of ICU stay. In each case the 5th to 95th centiles were used. In addition, the analysis was tested against changes in the cost of home NIV machines and equipment.

\section{RESULTS}

Thirteen patients were identified with severe COPD and recurrent acidotic exacerbations requiring acute NIV in hospital. No patients offered home NIV had been intolerant of it. The demographic data of the patients are shown in table 1. These represent a group of patients with severe COPD (mean $\mathrm{pH}$ on admission 7.31 during the year before home NIV, mean $\mathrm{FEV}_{1} 0.58$ l/min recorded in outpatient clinic).

\section{Consequences}

There was a statistically significant reduction in the rate of admission, total days in hospital, and length of admission per patient. Three patients spent time in the ICU (range 217 days) before starting home NIV; this fell to just one patient spending 4 days in the ICU with home NIV $(p=0.45)$. The mean number of outpatient appointments fell with the introduction of home NIV $(5 v 4, \mathrm{p}=0.14)$. There was no significant difference in arterial blood gas tensions at presentation with an acute exacerbation when patients did or 
Table 1 Characteristics and outcomes of study patients $(n=13)$

\begin{tabular}{|c|c|c|}
\hline & $\begin{array}{l}\text { No home } \\
\text { NIV }\end{array}$ & $\begin{array}{l}\text { With home } \\
\text { NIV }\end{array}$ \\
\hline Mean age (years) & $55(7.5)$ & \\
\hline$M: F$ ratio & $9: 4$ & \\
\hline $\mathrm{FEV}_{1}$ (clinic measurement) & $0.58(0.24)$ & \\
\hline \multicolumn{3}{|l|}{$\begin{array}{l}\text { Mean arterial gas tensions on } \\
\text { admission with acute exacerbation: }\end{array}$} \\
\hline $\mathrm{pH}$ & $7.31(0.02)$ & $7.31(0.04)$ \\
\hline $\mathrm{PcO}_{2}(\mathrm{kPa})$ & $9.94(0.86)$ & $9.55(1.26)$ \\
\hline $\mathrm{Po}_{2}(\mathrm{kPa})$ & $6.97(0.66)$ & $7.37(2.15)$ \\
\hline Admissions & $5(3)$ & $2(2)^{*}$ \\
\hline Total days in hospital & $78(51)$ & $25(25)^{\text {** }}$ \\
\hline Duration of admissions (days) & $17(10)$ & $8(7)^{\star * *}$ \\
\hline Days in ICU & $2(5)$ & $0.3(1)$ \\
\hline Outpatient appointments & $5(3)$ & $4(2)$ \\
\hline
\end{tabular}

did not have home ventilation. Mean (SD) arterial gas tensions when stable on home NIV were pH 7.38 (0.02), $\mathrm{Po}_{2}$ $8.3 \quad(1.5) \mathrm{kPa}, \quad \mathrm{PCO}_{2} \quad 6.9 \quad(0.9) \mathrm{kPa}$, bicarbonate 29.7 (3.0) $\mathrm{mmol} / \mathrm{l}$.

\section{Costs}

\section{Ward costs}

Cost data derived from the previously mentioned study ${ }^{16}$ are described in table 2. The first day of admission incurred greater costs because of a modest increase in nursing time involved in setting up the patient on NIV and recurring equipment costs (sterilising non-disposable equipment).

\section{Acute ventilation}

The purchase cost of an NIV machine was discounted to allow for a 5 year lifespan (discount rate 6\%), resulting in an equivalent annual cost of $£ 570$. Similarly, ward consumables (which would consist of a range of different size masks, headgear, and tubing) were discounted for a l year lifespan to an equivalent annual cost of $£ 551$. The initial equipment and consumables are fixed costs, independent of the number of inpatient episodes (assuming sufficient ventilators are

\section{Table 2 Cost centres}

\begin{tabular}{ll}
\hline Cost centres & $£$ \\
\hline Ward costs (daily) & \\
$\quad$ Capital costs & 78 \\
$\quad$ Nursing & 37 \\
Pharmacy & 3 \\
Intensive care & \\
$\quad$ Per day & 1277 \\
Additional ward NIV costs & \\
Per admissions: & \\
Nursing time & 5 \\
Recurring equipment cost & 12 \\
Annual fixed costs: & \\
Ventilator (each)* & 570 \\
Annual servicing & 28 \\
Equipment* & 551 \\
Training & 140 \\
Home NIV costs & \\
Per patient: & \\
Ventilator* & \\
Humidifier* & \\
Annual servicing & \\
Consumables** & \\
Annual fixed costs: & 179 \\
Respiratory nurse specialist & 28 \\
Outpatient attendance & 149 \\
\hline
\end{tabular}

Discounted at $6 \%$ *over 5 years or **over 1 year. $1 \mathrm{GBP}(£)=1.42$ Euro $(€)$. available at any one time). It is estimated that the unit requires approximately four ventilators to meet demand for acute inpatient NIV. However, not all ventilators will be used 365 days per year. The cost of providing inpatient NIV is therefore based on $90 \%$ occupancy of the ventilators, and the total cost of inpatient NIV was therefore valued as the annual discounted cost for four ventilators divided by 328 days (rather than 365) and multiplied by the total number of days used.

\section{Home ventilation}

Patients on home NIV have their own masks and tubing, with an equivalent annual cost of $£ 224$ allowing for an 8 month lifespan. Patients were also provided with a warm passover humidifier discounted for a 1 year lifespan $(£ 179)$.

\section{Training}

Based on the economic analysis by Plant et al, ${ }^{16}$ ongoing training of ward nursing staff consisted of just less than 1 hour per month. This was provided equally between a specialist registrar on the middle increment of the pay scale (£31 870) and an F grade nurse specialist ( $£ 20770$ ).

\section{Cost saving}

The mean cost per patient in the year before starting home NIV was $£ 13163$ (95\% CI $£ 8695$ to $£ 17631$ ) compared with $£ 4909$ (95\% CI $£ 2888$ to $£ 6930$ ) in the year with home NIV, a saving of $£ 8254$ (95\% CI $£ 4013$ to $£ 12495$ ( $p=0.002)$. There was a net saving of $£ 107298$ to the acute hospital by providing a home NIV service for this highly selected group of 13 patients with COPD (table 3 ).

\section{Sensitivity analysis}

A sensitivity analysis was performed on the cost analysis (table 4). The sensitivity analysis focused on admission rates, length of stay, ICU time, and ventilator costs. Despite testing the analysis with 5-95th centile ranges, there was no effect on the significance of the cost saving.

\section{DISCUSSION}

This study has identified a significant cost benefit to the acute hospital by the provision of a home NIV service for a selected group of patients with recurrent admissions with acidotic exacerbations of COPD. This cost saving is achieved by a reduction in hospital admission rates and length of stay. The home NIV service also resulted in a measurable (although not statistically significant) reduction in ICU occupancy and outpatient visits. These results are in keeping with other studies. ${ }^{12}$

This study has some limitations, however. It was a retrospective audit of just 13 patients. The patients were highly selected and, as a result, a group was studied that was most likely to derive benefit in terms of a reduction in admissions. While this may be a criticism, the study did not aim to evaluate the use of NIV in "allcomers" with COPD, but

Table 3 Cost data ( $n=13$ patients)

\begin{tabular}{lll}
\hline & No home NIV & Home NIV \\
\hline Ward costs & 121378 & 37916 \\
ICU costs & 31928 & 5108 \\
Ventilation (ward); $n=4$ & 14255 & 4477 \\
Ventilation (home); $n=13$ & 0 & 13007 \\
Respiratory nurse & 0 & 760 \\
Training & 140 & 140 \\
Outpatient appointments & 3417 & 2412 \\
Total costs (£) & 171118 & 63820 \\
Cost saving & \multicolumn{3}{c}{107298} \\
\hline I GBP $(£)=1.42$ Euro $(€)$. & \multicolumn{3}{l}{} \\
\hline
\end{tabular}




\begin{tabular}{llll} 
Table 4 Sensitivity analysis & & & \\
\hline Factor (during home NIV) & Baseline & Range tested & $\begin{array}{l}\text { Range of cost saving } \\
\text { (£/patient) }\end{array}$ \\
\hline Number of admissions & 2 & $0-6^{*}$ & $£ 11530-1996$ \\
Length of admission & 7 & $0-20^{*}$ & $£ 11926-5222$ \\
Days in ICU & 0.3 & $0-4^{*}$ & $£ 8900-3791$ \\
Cost of home ventilator & $£ 2400$ & $£ 24000$ & $£ 8253-6498$ \\
\hline *5-95th centiles. & & & \\
1 GBP $(£)=1.42$ Euro $(€)$. & & &
\end{tabular}

was specifically targeted at a group at a high risk of death who consume significant hospital resources. Furthermore, they had been shown to be able to tolerate and benefit from NIV. The correct selection of patients most likely to benefit from any intervention is part of the skill of clinical medicine and also ensures a cost effective use of resources. As with any uncontrolled study, the possibility that the changes seen were due to chance alone needs to be considered. These results may reflect regression to the mean; patients were started on NIV when they were perceived to be at their worst. Any improvement in the subsequent period may reflect natural variation in the disease and not a direct effect of home NIV. However, the magnitude of the changes seen makes this unlikely. A prospective randomised controlled trial would have been more rigorous, and the data from this study may inform the power calculation for such a study in the future. However, there are important ethical issues which may make performing a prospective randomised controlled trial difficult. Patients who have experienced, tolerated and benefited from inpatient NIV and who themselves consider that NIV would obviate the need for future admission and improve their quality of life may be very reluctant to enter a study in which allocation to this treatment would be based on chance alone.

The possibility that the change in admission rates could be attributed to other confounding factors needs to be addressed. All patients were receiving regular nebulised bronchodilators before starting NIV. No patient had a change in treatment with oral theophyllines or long term oxygen therapy during the period studied. While most of the patients $(n=9)$ were already attending this centre in the year before commencing NIV, four were referred from other centres for assessment and commencement of NIV. It is possible that there will have been a "centre" effect but, other than commencing NIV, there were no other changes in medical treatment.

The time period examined was the year before and the year after starting NIV. This was chosen to minimise the effect of deterioration in the underlying condition in the absence of a control group. In this small group of patients, where some patients are still alive at 40 months, a Kaplan-Meier analysis suggests a median survival with the provision of home NIV of 29 (14) months. This compares very favourably with the improvement in survival achieved by providing acute NIV for exacerbations of COPD (16.8 months) and with conventional treatment alone (13.4 months), ${ }^{20}$ and is similar to that described by Jones. ${ }^{12}$ If NIV does indeed prolong life in these patients, then it is possible that domiciliary NIV just postpones these costs to the acute hospital to a later date and that, if the study were extended, the savings from NIV would eventually be lost. Patients would have to have a median survival of over 40 months for the increased costs associated with longer survival to outweigh the cost savings of domiciliary NIV compared with the provision of acute NIV only. It is also possible that prolonged survival comes with the cost of life of marginal quality. However, other studies have shown that health status and quality of life are maintained with domiciliary NIV. ${ }^{13}$ This could be evaluated further by an economic analysis of the outcome in pounds per quality adjusted life year (QALY). This is beyond the scope of this study, but the data may be useful to inform the power calculation for future studies.

This study has identified costs and placed values on these costs from the acute hospital perspective. The acute hospital has the most to be gained financially from reducing hospital admissions, but this may result in an increased demand on primary care services. The costs of this were not addressed in this study. However, for the provision of home NIV to become cost neutral, the increased burden on primary care would have to be of the order of $£ 8254$ - that is, in excess of 450 consultations per patient or 200 home visits. ${ }^{1}$ The study by Jones $e t \mathrm{al}^{12}$ actually found a reduction in general practitioner consultations when NIV was instituted.

In conclusion, NIV is a relatively new health technology for which there are an ever increasing number of indications. Its use, however, should be evidence based, ideally on the basis of prospective randomised controlled trials, but these are not always feasible or ethical. Cost effectiveness is an important requirement before any new intervention is accepted. This study suggests that domiciliary NIV for a highly selected group of patients with recurrent admissions to hospital with acidotic exacerbations of their COPD saves the acute hospital a significant amount of money. Further longer term studies are needed to address the quality of life of patients and costs to society. This study provides useful data for the design of such studies.

\section{ACKNOWLEDGEMENTS}

The authors would like to thank Professor Christine Godfrey for her assistance in the economic aspects of this manuscript.

\section{Authors' affiliations}

J M Tuggey, P K Plant, M W Elliott, Department of Respiratory Medicine, St James's University Hospital, Beckett Street, Leeds LS9 7TF, UK

The department has received equipment on loan from ventilator companies. MWE has received honoraria from Respironics and Teijin for lecturing.

JT was funded by the Northern and Yorkshire NHS Executive.

\section{REFERENCES}

1 Netton A, Curtis L. Unit costs of health and social care. Canterbury: Personal Social Services Research Unit, 2000

2 Bott J, Carroll MP, Conway JH, et al. Randomised controlled trial of nasal ventilation in acute ventilatory failure due to chronic obstructive airways disease. Lancet 1993;341:1555-7.

3 Brochard L, Mancebo J, Wysocki M, et al. Noninvasive ventilation for acute exacerbations of chronic obstructive pulmonary disease. N Engl J Med 1995:333:817-22

4 Kramer N, Meyer TJ, Meharg J, et al. Randomized, prospective trial of noninvasive positive pressure ventilation in acute respiratory failure. Am J Respir Crit Care Med 1995;151:1799-806.

5 Plant PK, Owen JL, Elliott MW. Early use of non-invasive ventilation for acute exacerbations of chronic obstructive pulmonary disease on general respiratory wards: a multicentre randomised controlled trial. Lancet 2000;355:1931-5.

6 Angus RM, Ahmed AA, Fenwick $\sqcup$, et al. Comparison of the acute effects on gas exchange of nasal ventilation and doxapram in exacerbations of chronic obstructive pulmonary disease. Thorax 1996:51:1048-50. 
7 Celikel T, Sungur M, Ceyhan B, et al. Comparison of noninvasive positive pressure ventilation with standard medical therapy in hypercapnic acute respiratory failure. Chest 1998;114:1636-42.

8 Thys F, Roeseler J, Reynaert $M$, et al. Noninvasive ventilation for acute respiratory failure: a prospective randomised placebo-controlled trial. Eur respiratory failure: a prospir J 2002;20:545-55.

9 Lightowler JV, Wedzicha JA, Elliott MW, et al. Non-invasive positive pressure ventilation to treat respiratory failure resulting from exacerbations of chronic obstructive pulmonary disease: Cochrane systematic review and metaanalysis. BMJ 2003:326:185.

10 Plant PK, Owen J, Elliott MW. One year period prevalance study of respiratory acidosis in acute exacerbation of COPD; implications for the provision of non-invasive ventilation and oxygen administration. Thorax 2000;55:550-4.

11 Leger P, Bedicam JM, Cornette A, et al. Nasal intermittent positive pressure ventilation. Long-term follow-up in patients with severe chronic respiratory insufficiency. Chest 1994; 105:100-5.

12 Jones SE, Packham S, Hebden $M$, et al. Domiciliary nocturnal intermittent positive pressure ventilation in patients with respiratory failure due to severe COPD: long term follow up and effect on survival. Thorax 1998;53:495-8.
13 Perrin C, El Far Y, Vandenbos F, et al. Domiciliary nasal intermittent positive pressure ventilation in severe COPD: effects on lung function and quality of life. Eur Respir J 1997; 10:2835-9.

14 Clini E, Sturani C, Rossi A, et al. The Italian multicentre study on noninvasive ventilation in chronic obstructive pulmonary disease patients. Eur Respir J 2002;20:529-38.

15 Casanova C, Celli BR, Tost L, et al. Long-term controlled trial of nocturnal nasal positive pressure ventilation in patients with severe COPD. Chest 2000;118:1582-90.

16 Plant PK, Owen JL, Elliott MW. Cost effectiveness of ward based non-invasive ventilation for acute exacerbations of chronic obstructive pulmonary disease: economic analysis of randomised controlled trial. BMJ 2003;326:956.

17 British National Formulary. BMA and Royal Pharmaceutical Society of Great Britain, 2001.

18 Brown F. Health services cost index, London: HMSO, 2001.

19 HM Treasury. Economic appraisal in central government: a technical guide for government departments. London: HMSO, 1997.

20 Plant PK, Owen JL, Elliott MW. Non-invasive ventilation in acute exacerbations of chronic obstructive pulmonary disease: long term survival and predictors of in-hospital outcome. Thorax 2001;56:708-12.

\section{LUNG ALERT}

\section{No effect of nebulised adrenaline on clinically important outcomes in viral bronchiolitis}

$\Delta$ Wainwright C, Altamirano L, Cheney M, et al. A multicenter, randomized, double-blind, controlled trial of nebulized epinephrine in infants with acute bronchiolitis. N Engl J Med 2003;349:27-35

$\mathrm{T}$

he evidence that oxygen is the only effective treatment in viral bronchiolitis continues to mount. The largest double blind, randomised, placebo controlled trial to date of nebulised adrenaline (epinephrine) showed no improvement in duration of hospital stay/time until ready for discharge with adrenaline compared with placebo. Indeed, in those with more severe bronchiolitis, adrenaline was associated with an increase in the duration of hospital stay. There was no improvement in oxygenation or clinical score in the group receiving adrenaline. The best predictor of severity of bronchiolitis and duration of stay in hospital was oxygen saturation in room air at admission. Interestingly, oxygen saturation at admission was also a good predictor of severity in acute asthma.

Previous studies of the role of adrenaline in bronchiolitis have shown improved respiratory mechanics and clinical severity scores but the methodology has been flawed with too few patients, inclusion of older infants with previous wheezing episodes, and lack of clinically important outcomes (for example, duration of hospitalisation or need for intensive care/mechanical ventilation). Bronchodilators have not been shown to be effective in bronchiolitis although a trial of their use is common, especially in older infants with a personal or family history of atopy. Wainright's paper suggests that adrenaline is not effective in this subgroup, although the study was not sufficiently powered to answer this question.

It would appear that, for the moment at least, supplemental oxygen and supportive care remain the only effective treatment for viral bronchiolitis.

D Wood

Royal Children's Hospital, Parkville, Australia; damian.wood@rch.org.au 